\title{
Fetal Retinoid Syndrome
}

National Cancer Institute

\section{Source}

National Cancer Institute. Fetal Retinoid Syndrome. NCI Thesaurus. Code C98929.

A teratogenic disorder observed in a newborn or child of a mother who was exposed to retinoids during pregnancy. Manifestations include growth delay, skull, facial, heart, and central nervous system malformations. 